'Guntrip, H. J. S. (1971) Psychoanalytic Theory, Therapy and the Self. London: Hogarth Press; New York: Basic Books.

6 _ (1968) Schizoid Phenomena, Object Relations and the Self. London: Hogarth Press; International Psycho-Analytical Library, No. 77.

7 (1975) My experiences of analysis with Fairbairn and Winnicott. International Review of Psycho-Analysis, 2, 145.
${ }^{8}$ Glatzer, H. T. \& Evans, W. N. (1977) On Guntrip's analysis with Fairbairn and Winnicott. International Journal of Psychoanalytic Psychotherapy, 6, 81-98.

'ElGEN, M. (1981) Guntrip's analysis with Fairbairn and Winnicott: A critique of Glatzer and Evans. Contemporary PsychoAnalysis, 17, No. 1.

\title{
Educational Programmes for General Practitioners and Clinical Assistants in the Mental Handicap Service
}

\author{
Joan Bicknell, Professor of the Psychiatry of Mental Handicap, St George's Hospital, London SW 17
}

The current trend towards community care for mentally handicapped people means that general practitioners have greater opportunities to meet mentally and multiply handicapped people living in the family home or in small units in the community. In addition, an increasing number of large long-stay mental handicap hospitals have delegated the reponsibility for primary care to local GPs, frequently employed as clinical assistants for this purpose. This is having the welcome effect of allowing the psychiatrist and the trainee in psychiatry to follow their particular interests and develop their own treatment skills.

The success of such a primary care service depends on local interest from GPs, their job description and the level of support available to them from the multidisciplinary team, including the psychiatrist and the hospital administrator. For some the role is still seen to be small and is restricted to somatic care with no involvement in the multidisciplinary discussions. Others only cover the service outside normal working hours. An increasing number of GPs are being given a wider remit, and yet some may not feel that they have the training, the skills, or day-to-day contact with other team members to offer a full primary care service to this patient group.

To remedy this situation in one London Borough, train ing for four GPs in the Mental Handicap Service began in 1979, with six evenings devoted to the following topics: aetiology of mental handicap; epidemiology and prevention and mental handicap; patterns of care; additional handicaps; psychiatric illnesses and behaviour disorders; and treatment techniques.

Enthusiasm for this initial course resulted in monthly meetings for all doctors in the service, i.e. GPs, psychiatrists and visiting consultants, together with the chiropodist, audiometrician and pharmacist, where they learned more of each other's roles. A recent variation has been to hold psychopharmacology seminars where case histories spreading over many years have been presented with particular reference to diagnosis and the uses and abuses of medication, drug interactions and side effects. This programme was then complemented by two monthly educational visits when some of these doctors would visit another service and together appraise their findings.

Despite many shortcomings, this programme resulted in a cohesive group of GPs who together have been able to provide a total primary care service, including basic psychiatry and preventive medicine, with a 24-hour emergency service for a 200-bed hospital. In one community unit, the GP has extended his role to primary care adviser to the Community Mental Handicap Team and has been a valuable link with local GPs.

The result of working, learning and visiting together has been a rise in standard of primary care and psychiatry for mentally handicapped people in the long-stay hospital, in community units, in hostels and their own homes within the catchment area served.

Arising from the enthusiasm for this range of learning opportunities, being aware of the current trends in the provision of community care and conscious of the improvements in the service already witnessed, an experimental twoday residential course was set up in November 1983 by the Regional Adviser in General Practice, Dr Trevor Silver, and myself as the Regional Postgraduate Tutor in Mental Handicap.

The course was advertised through the auspices of the British Postgraduate Medical Federation, throughout the four Metropolitan Regional Health Authorities for GPs and clinical assistants involved or interested in the services for mentally handicapped people.

Thirty GPs and clinical assistants attended the course, including some GP trainees and their trainers. There were 12 people from several disciplines participating in the teaching, all associated with the Section of Psychiatry of Mental Handicap, St George's Hospital Medical School. The course started with brief introductions, a resume of each person's professional and personal contact with mental handicap and what he or she wanted from the course. A variety of teaching methods were used.

Didactic lectures: these covered the history of care of mentally handicapped people, organization of services at present and plans for the future; the causes and prevention of 
mental handicap; biological and ethical considerations; additional handicaps; diagnostic challenges; and psychiatric illness in mentally handicapped people. This teaching, which included time for discussion, ensured an adequate baseline of knowledge. Small group work: this involved the discussion of videos illustrating various lifestyles and biographies of handicapped people. Topics here included bereavement and loss; sexuality; risk taking; the sickness model; and medication and its abuse. There was also an experiential game illustrating some of the challenges and dilemmas in the planning of services in the long-stay sector. Activity workshops: these were enthusiastically received and involved a behavioural approach to skill building and treatment of behaviour disorders; the role of the physiotherapist for mentally handicapped people; and non-verbal communication systems with special reference to MAKaton. Research papers and personal viewpoints: presentations here included 'Long-acting phenothiazines in mental handicap practice' and 'The viewpoint of the Community Mental Handicap Team'.

Participants were asked to evaluate the course and an analysis of their comments yielded a positive response. There was a unanimous request for a feedback meeting some months after the course to be held in a Mental Handicap Service where the skills that had been learned could be seen in practice.

The value of such a course can only be measured by a change in awareness of the medical needs and of the roles of others in the lives of mentally handicapped people, and by an improvement to the medical service wherever mentally handicapped people might be. My impression was that the course will make a significant contribution towards that end and the model might be adopted by others who are committed to raise the standard of primary care through a better understanding of the needs and vulnerabilities of this patient group.

\title{
Saskatchewan Secure Unit
}

\author{
Martin G. Livingston, Senior Lecturer in Psychological Medicine, University of Glasgow
}

The British approach to administrative problems is often to accumulate more and more evidence for changes which are obsolete before enaction. Such a fate seems likely to happen to plans for the management of the psychiatrically disturbed offender following several reports. ${ }^{1,2,3}$ It was interesting, therefore, this summer to work as a locum consultant in a Saskatchewan forensic psychiatric hospital.

The Regional Psychiatric Centre (Prairies) located in Saskatoon, is a secure hospital accepting referrals from the prisons, the courts and correctional centres exclusively. The Centre was opened in 1978 and is one of three similar units in Canada, set up following a Committee of investigation into the management of the forensic psychiatric patient.

The building is a polyhedron with central courtyard. Neatly tended lawns and bedding flowers surprise; the entrance is as formal as the adjacent prairie is informal. Access is gained to the five locked patient areas by means of the perimeter corridor. Doors are opened centrally and are under constant video surveillance. Once inside the patient areas, access to day rooms is permitted by security staff, the doors being under remote control.

Patient facilities, in line with American standards, included the constant availability of coffee and direct access to a music room on the ward. A well-equipped gymnasium was also available in the hospital, together with a good library. Furniture, although modern and functional, was spartan. There was little or no evidence of vandalism and graffitti were a minimal problem. The hospital had space for approximately 100 beds.
The hospital has several functions. The first provides for a two to three-week period of assessment by psychiatric, psychological, nursing and security staff. This period culminates in a Case Conference. The patient is invited to attend part of the proceedings and conclusions regarding disposal are discussed with him during the conference, after he has had an opportunity to put his point of view.

In addition to assessment, there are units for the treatment of sexual offenders, chronic psychotics and severe personality disordered individuals, as well as a therapeutic community orientated towards the more intact individual, generally also with personality difficulties. Treatment is within a group setting and involves the combination of interpretative and directive approaches.

Sexual offenders in Canada, as in the UK, are generally subject to abuse and assault from other prisoners. A secure psychiatric unit is able to afford protection as well as treatment since, in such an institution, many other inmates have been rejected by the general prison population for a variety of reasons.

The hospital also has an isolation unit in which particularly disturbed individuals can be nursed in single locked rooms whilst under constant 24-hour surveillance. Individuals were generally kept in such circumstances for, at most, a few days. This was a remarkable achievement when one considers that commonly such individuals were referred because they could not function or could not be managed within the penitentiary system, generally because of selfdestructive or aggressive behaviour, deemed to be related to 